\title{
استخدام الوسائل الصورة في تحسين مهارة كتابة اللغة العربية في مدرسة الثانوية الإسلامية الأهلية دار الاستقامة بادانج سيدمبوان \\ ${ }^{1}$ Ismail Baharuddin, ${ }^{2}$ Surya Ningsih \\ Pendidikan bahasa arab Iain padangsidimpuan \\ E-mail: erawadi@iain-padangsidimpuan.ac.id
}

$$
\begin{aligned}
& \text { تجريد } \\
& \text { مهارة الكتابة مهارة الأخير من مهارات اللغات، المشكلة الأساسية في هذا البحث هي كيف ترقية } \\
& \text { اهتمام التلاميذ على تعليم مهارة الكتابة باستخدام وسائل الصورة. الأهداف لهذه البحث هي ترقية } \\
& \text { اهتمام التلاميذ على تعليم مهارة الكتابة باستخدام وسائل الصورة. الطريقة المستعملة في هذا البحث } \\
& \text { هو بحث الفصل الدراسي هو بحث يصف حدوث العلاقة السببية من العلاج مع شرح ما يحدث عند } \\
& \text { اعطاء العلاج. النتائج من هذا البحث هي استخدام وسائل الصورة ترقية لاهتمام التلاميذ وقدراهم في } \\
& \text { تعليم مهارة الكتابة، وهذاه النتائج استنادا إلى دورة البحث التالي؛ تمخضت النتائج عن نتائج ما قبل } \\
& \text { الدورة عن بr\% وعن النتائج التي حققتها الدورة الأولى بنسبة \ه\% وعن نتائج الدورة الثالثة التي بلغت } \\
& \text { •^.٪. الخلاصة من هذا البحث اهتمام التلاميذ على تعليم مهارة الكتابة باستخدام وسائل الصورة } \\
& \text { ترقية. } \\
& \text { الكلمة المفتوحة: استخدام الوسائل الصورة؛ مهارة كتابة اللغة العربية }
\end{aligned}
$$

\section{Abstrak}

Keterampilan menulis merupakan keterampilan terakhir dari keterampilan berbahasa. Masalah utama dalam penelitian ini adalah bagaimana menumbuhkan minat siswa dalam pemjaran keterampilan menulis menggunakan sarana gambar. Tujuan dari penelitian ini adalah untuk meningkatkan minat siswa dalam pembelajaran keterampilan menulis dengan menggunakan media gambar. Metode yang digunakan dalam penelitian ini adalah penelitian tindakan kelas yang menggambarkan terjadinya hubungan sebab akibat dari suatu perlakuan dengan penjelasan tentang apa yang terjadi ketika perlakuan tersebut diberikan، dan menjelaskan seluruh proses dari awal pemberian perilaku hingga efek tindakan. Hasil dari penelitian ini adalah penggunaan sarana gambar untuk meningkatkan minat dan kemampuan siswa dalam pembelajaran keterampilan menulis. Hasil ini didasarkan pada siklus penelitian berikut; Hasil pra sesi 36\% siklus I 56\% ، dan siklus III 80\%. Kesimpulan dari penelitian ini adalah minat siswa dalam mengajar keterampilan menulis dengan menggunakan sarana image promotion.

Keyword: Penggunaan media gambar; Maharah kitabah 
مهاراة الكتابة الرائعة هي أعلى المهارات بين المهارات الاربع في اللغة العربية. تلك المهارات الاستماع إلى الكلام القراءة والكتابة. الكتابة هنا ليست سهلة مثل الكتابة باستخدام اللغة الثانية و الأندونيسية، لأن الكتابة المشار إليها في هذه الدراسة هي تاليف أو وصف شيء فكر أو شعربة الطلاب ثم سكبوا في كتابة بحيث يصبح تكوين الجمل باستخدام اللغات الاجنبية أو العربية.

الكتابة هي عبارة عن بجموعة من الكلمات المنظمة والمنظمة. معنى الكتابة في نظرية المعرفة عبارة عن بحموعة من الكلمات التي تتكون وتتضضمن معني، لان الكتابة لن تتشكل الا اذا كانت هناك كلمة عادية. مع الكتابة، يمكن للناس أن يصبوا تعبيراتم بحرية وفقا لما يدور في ذهنهم. من خلال كتابة التعبيرات المكتوبة، يؤمل ان يتمكن القراء من فهم ما يريد المؤلف التعبير عنه.

الكتابة هي أعلى واصعب مهارة بين المهارات الثلاث المذكورة. أن الشعور الصعب الذي يسعربه الطلاب في العمل في الواجبات وتقييم تعلم اللغة العربية، وخاصة في الكتاب، أمر طبيعي، لأن اللغة العربية ليست لغة اجتمائية في بيعتها أو بحتمعها ولكنها تحصل عليها في المدرسة. ومن أجل التغلب عل هذه المشكلة، قد يكون من الافضل استحدام وسيلة لتعلم اللغة العربية. خاصة في الكتاب اومهارات الكتابة، يجب ان يكون هناك دورلصورة الوسائل،بحيث تحتاج نتيجة او مهارة الكتابة هذه الي دور وسائل الصورة، بحيث تكون نتاعج تعلم الطلاب افضل من ذي قبل، كما تزداد غالبية درجات.

' Mahiyatuha wa Turuqu Tadrisuha، al-Maharah al-Lughawiyah، Ulyan، احمد فو عد محمود)

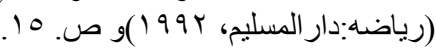
'جيجيف كوستندي وبممنج سوتفجو، Media Pembeajaran Manual dan Digital، ( بوخور:خالييا 
Thariqah IImiyah; Jurnal IImu-IImu Kependidikan dan Bahasa Arab

Vol. 9. No. 2 Desember 2021

وفي انشطة الكتابة، يجب أن يكون الكاتب ماهرا في استخدام دراسة الخط، وهيكل اللغة، والمفردات. تستخدم مهارات الكتابة لتسجيل القراء وتسجيلهم واقناعهم ولابلاغ عنهم والتأثير عليهم. لايمكن تحقيق التعلم بشكل جيد الا من خلال الطلاب الذين يمكنهم بتميع طريقة تفكير تعبر بوضوح وسلاسة وتواصل. هذا الوضوح يعتمد على العقل

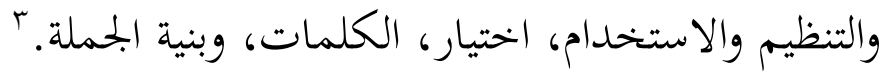

الكتابة هي نشاط تواصلي يتم تنفيذه دون دعم ضغط الصوت والنغمة والايماءات وبدون مواقف مثل تلك التي تحدث في انشطة الاتصال الشفهي.وبالتالي يجب ان يكون الكاتب جيدا في استخدام الكلمات والتعبيرات والجمل وايضا استخدام وظيفة الموقف لتو صيل الاخرين وأبلاغهم ووصفهم واقتراح شيء ما. أمابا لنسبة للعناصر المكتوبة فهي الكلمة أو أصغر وحدة للكلمات من جملة أو عنصر أساسي في تكوين الجملة هو مقدار أو بحموعة من الكلمات التي يمكن ان تساعد في فهم المعنى أو كلمة واحدة بناء على كلمات اخرى هي عوامل أو فقرات وموقع ويب. صرح أبو حامد أن مهارات الكتابة لها ثلاثة جوانب: أ) الكفاءة في تشكيل الحروف واتقان الهجاء، ب) المهارات لتحسين الساخنة، ج) الكفائة تلد الافكار والمشاعر مع الكتابة.

المكتابة لما أنوأع وهي على النحو:ْ أ) معرض بسيط، على سبيل المثال تعاريف الكلمات اليومية أو التعليقات القصيرة التي يسمعها الطلاب، ب) سرد أو قصة تكتب احداثا تم اختبارها للتو من قبل الطلاب، ب) الوصف،وهذاهو، والكتابة باستخدام الكلمات الصراع لدية خطة لدعم رسالة دقيقة، ج) خطاب، أي كتابة خطاب يحتوي

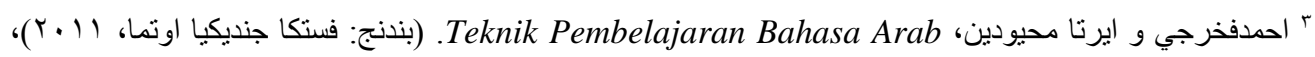


Thariqaah IImiyah; Jurnal IImu-IImu Kependidikkan dan Bahasa Arab

Vol. 9. No. 2 Desember 2021

على عنصر السرد أو الوصف، على سبيل المثال، أو خطاب العائلة والرسالة الرسمية، د)

الخلق، وهذاهو، انساء المتقدمة لان الكاتب هو مطلوب للتعبير عن الحجج له بشكل مناسب، ه) الخيال، ان انساء يتطلب مخيلة عالية في هذه الحالة عوامل المواهب تصبح محدد النجاح.

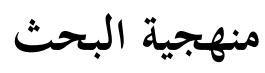

الطريقة المستعملة في هذا البحث هو بحث الفصل الدراسي هو بحث يصف حدوث

العلاقة السببية من العلاج مع شرح ما يحدث عند اعطاء العلاج. وشرح العملية برمتها من بداية اعطاء السلوك الى تاثير العلاج.' وأما تعريف الفرضية هي إجابة مؤقتة لصياغة

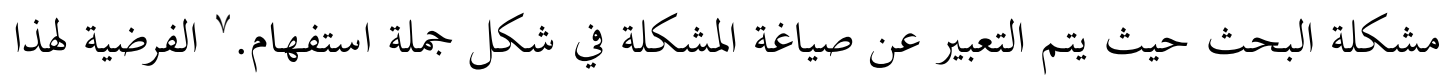
البحث هي اجابة مؤقتة للمشاكل التي اثيرت في الدراسة. في بحث العمل الفصولي الذي اجراه الطلاب نهو مدرسة الصف السابع الثانوية الخاصة مدرسة داراستقامة هوتا الاسلامية الداخلية في هوتا بادنج. ذكرت الفرضية أن وسائل الصورة يمكن أن تحسن فهم الطلاب في تعلم اللغة العربية. الهيكل الفكرية لهذا البحث؛ المواد العربية التي تحتاج حقا الى منهجية أو وسائل في التعلم. مع المواد المتعلقة بالطبيعة في جميع أنحاء المدرسة وكل يوم. مثل البشر، الحيوانات، النباتات و الاشياء من حولم. ولن يتم تشغيل عملية التعلم بالشكل الأمثل اذا كانت المادة تواجه

\begin{tabular}{|c|c|}
\hline$X$ & $\mathrm{Y}$ \\
\hline تعديل الوسائل & الطلاب قادرون على \\
\hline
\end{tabular}

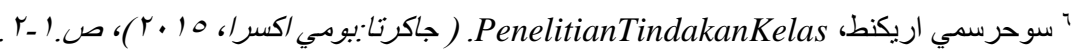

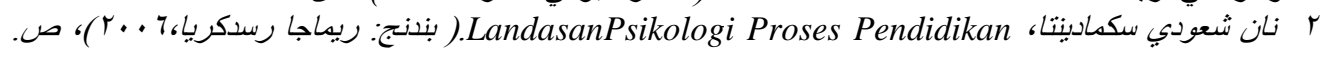

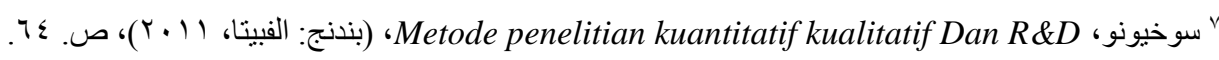


Thariqaah IImiyah; Jurnal IImu-IImu Kependidikkan dan Bahasa Arab

Vol. 9. No. 2 Desember 2021

\begin{tabular}{|c|c|c|c|}
\hline & تتؤثرعلى القدرة & التكيف مع المفردة & \\
\hline الوستخدام & & لفهسين و المواد تسهيل الطلاب & وسائل الصورة \\
\hline المفتخدام & & مفردات في الجملة فعلية قادرون على جعل & \\
\hline
\end{tabular}

\section{ا ـ منتائج قبل الدورة}

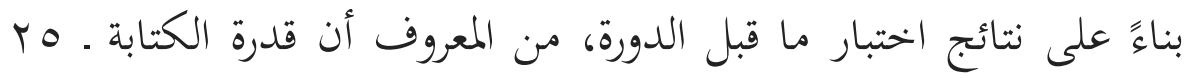
طالبًا ممن هم موضوع البحث جيدة جلدًا. يستطيع الطالب كتابة مقالات باللغة العربية تتعلق بالحياة اليومية أو الموضوعات التي حددها المعلم. عند النظر إليها من حيث النطق والتجويد وإتقان المفردات وكذلك الحد الأقصى للعرض التقديمي للكتابة بناءً على الاختبارات التي أجراها الباحثون ، فإن قدرة الطلاب على ولى الكتابة لم تصل إلى الحد الأقصى. لمزيد من التفاصيل ، فيما يلي القدرة على كتابة مقالات الطلاب بناءً على اختبارات ما قبل التصرف: نتئيجة البيانات اجراء قبل العمل

\begin{tabular}{|c|c|c|c|c|}
\hline \multirow[b]{2}{*}{ رقم } & \multirow[b]{2}{*}{ الاسم } & \multirow[b]{2}{*}{ القيمة } & \multicolumn{2}{|c|}{ كمال } \\
\hline & & & كمال & ليست كاملة \\
\hline 1 & ابدل حميد & 75 & $\checkmark$ & \\
\hline 2 & احمد اريفن & 15 & & $\checkmark$ \\
\hline 3 & احمد عريندي & 40 & & $\checkmark$ \\
\hline
\end{tabular}


Thariqah IImiyah; Jurnal IImu-IImu Kependidikan dan Bahasa Arab

Vol. 9. No. 2 Desember 2021

\begin{tabular}{|c|c|c|c|c|}
\hline 4 & عيدل فهله بتوبار & 70 & $\checkmark$ & \\
\hline 5 & الفين سهرين & 15 & & $\checkmark$ \\
\hline 6 & دانيل سهفطرا & 25 & & $\checkmark$ \\
\hline 7 & دافيد مرتوا & 10 & & $\checkmark$ \\
\hline 8 & فهمي & 55 & & $\checkmark$ \\
\hline 9 & فرينط & 75 & $\checkmark$ & \\
\hline 10 & احواند لوبس & 10 & & $\checkmark$ \\
\hline 11 & لحودني سمامورا & 15 & & $\checkmark$ \\
\hline 12 & محمد موليا لوبس & 70 & $\checkmark$ & \\
\hline 13 & محمد ديدت & 20 & & $\checkmark$ \\
\hline 14 & محمد سهريل & 45 & & $\checkmark$ \\
\hline 15 & فرحان & 74 & $\checkmark$ & \\
\hline 16 & رحول انديك & 74 & $\checkmark$ & \\
\hline 17 & رزكي سهنطرا & 20 & & $\checkmark$ \\
\hline 18 & ريحان حبيبي & 25 & & $\checkmark$ \\
\hline 19 & شحدان & 70 & $\checkmark$ & \\
\hline 20 & شولتان سيرجر & 25 & & $\checkmark$ \\
\hline
\end{tabular}


Thariqaah IImiyah; Jurnal IImu-IImu Kependidikkan dan Bahasa Arab

Vol. 9. No. 2 Desember 2021

\begin{tabular}{|c|c|c|c|c|}
\hline 21 & سحرول رندي & 25 & & $\checkmark$ \\
\hline 22 & رحمات سليح & 70 & $\checkmark$ & \\
\hline 23 & توفق الحم & 25 & & $\checkmark$ \\
\hline 24 & وحيودي رمبي & 20 & & $\checkmark$ \\
\hline 25 & واريادي & 75 & $\checkmark$ & \\
\hline \multicolumn{4}{|c|}{ عدد الدرجات التي تم الحصول عليه } & 1.043 \\
\hline \multicolumn{4}{|c|}{ القيمة المتوسط } & $41 ، 72$ \\
\hline \multicolumn{4}{|c|}{ أقص عدد من النقط } & 75 \\
\hline \multicolumn{4}{|c|}{ Nilai $<$ KKM } & 16 \\
\hline \multicolumn{4}{|c|}{ Nilai $>$ KKM } & 9 \\
\hline \multicolumn{4}{|l|}{ غائب } & - \\
\hline
\end{tabular}

Presentase kekuatan : $\mathrm{P}=\frac{\text { Jumlah siswa yang tuntas belajar }}{\text { Jumlah siswa maksimum }} \times 100 \%$

$$
\begin{aligned}
& =\frac{9}{25} \times 100 \% \\
& =36 \%
\end{aligned}
$$

انطلاقًا من نتائج ما قبل الدورة، فإن الطلاب الذين يكملون أنشطة

التدريس والتعلم حول كتابة المقالات باللغة العربية هم و أشخاص من أصل هن

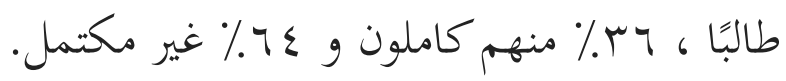


Thariqah IImiyah; Jurnal IImu-IImu Kependidikan dan Bahasa Arab

Vol. 9. No. 2 Desember 2021

$$
\text { r ـ نتائج الإجراءات في الدورة الأولى }
$$

نتائج تنفيذ مهارات الكتابة لدى الطلاب من حيث النطق، وإتقان المفردات

$$
\text { والتجارب عند التحدث أو القراءة في الدورة الأولى، وهي: }
$$

يمكن ملاحظة أن الطلاب الذين أفهوا تعلم ع ا من أصل هب شخصًا. درجة اكتمال مهارات الكتابة للطلاب في 7 ه ٪ من نتائج العمل في الدورة الثانيةنتائج تنفيذ اختبار مهارات الكتابة للطلاب من حيث النطق، وإتقان المفردات والعرض

\begin{tabular}{|c|c|c|c|c|}
\hline \multirow[b]{2}{*}{ رقم } & \multirow[b]{2}{*}{ الاسم } & \multirow[b]{2}{*}{ القيمة } & \multicolumn{2}{|c|}{ كمال } \\
\hline & & & كمال & ليست كمال \\
\hline 1 & ابدل حميد & 75 & $\sqrt{ }$ & \\
\hline 2 & احمد اريفن & 30 & & $\checkmark$ \\
\hline 3 & احمد عريندي & 40 & & $\checkmark$ \\
\hline 4 & عيدل فهله بتوبار & 70 & $\checkmark$ & \\
\hline 5 & الفين سهرين & 15 & & $\checkmark$ \\
\hline 6 & دانيل سهفطرا & 73 & $\checkmark$ & \\
\hline 7 & دافيد مرتوا & 15 & & $\checkmark$ \\
\hline 8 & فهمي & 74 & $\checkmark$ & \\
\hline
\end{tabular}
التقديمي في قراءة نتائج المقال في الدورة الثانية، وهي: 
Thariqah IImiyah; Jurnal IImu-IImu Kependidikan dan Bahasa Arab

Vol. 9. No. 2 Desember 2021

\begin{tabular}{|c|c|c|c|c|}
\hline 9 & فرينط & 75 & $\checkmark$ & \\
\hline 10 & اكووند لوبس & 15 & & $\sqrt{ }$ \\
\hline 11 & لحودين سمامورا & 20 & & $\checkmark$ \\
\hline 12 & محمد مليا لوبس & 70 & $\checkmark$ & \\
\hline 13 & محمد ديديت اسوال & 20 & & $\checkmark$ \\
\hline 14 & محمد سهريل & 73 & $\checkmark$ & \\
\hline 15 & فرحان & 74 & $\checkmark$ & \\
\hline 16 & رحول انديك & 70 & $\checkmark$ & \\
\hline 17 & رزكي سهفطرا & 20 & & $\checkmark$ \\
\hline 18 & ريجان حبيبي & 25 & & $\checkmark$ \\
\hline 19 & شحدان & 70 & $\checkmark$ & \\
\hline 20 & شولتان سيرجر & 25 & & $\checkmark$ \\
\hline 21 & سحرول رندي & 75 & $\checkmark$ & \\
\hline 22 & رحمات سليح & 70 & $\checkmark$ & \\
\hline 23 & توفق الحم & 75 & $\checkmark$ & \\
\hline
\end{tabular}


Thariqaah IImiyah; Jurnal IImu-IImu Kependidikkan dan Bahasa Arab

Vol. 9. No. 2 Desember 2021

\begin{tabular}{|c|c|c|c|c|}
\hline 24 & وحيودي رمبي & 40 & & $\checkmark$ \\
\hline 25 & واريادي & 73 & $\checkmark$ & \\
\hline \multicolumn{4}{|c|}{ عدد الدرجات التي تم الحصول عليه } & 1.282 \\
\hline \multicolumn{4}{|c|}{ القيمة المتوسط } & $51 ، 28$ \\
\hline \multicolumn{4}{|c|}{ أقص عدد من النقط } & 75 \\
\hline \multicolumn{4}{|c|}{ Nilai $<$ KKM } & 11 \\
\hline \multicolumn{4}{|c|}{ Nilai $>$ KKM } & 14 \\
\hline \multicolumn{4}{|l|}{ غائب } & - \\
\hline
\end{tabular}

$$
\text { Presentase kekuatan : } \begin{aligned}
\mathrm{P} & =\frac{\text { Jumlah siswa yang tuntas belajar }}{\text { Jumlah siswa maksimum }} \times 100 \% \\
& =\frac{14}{25} \times 100 \% \\
& =56 \%
\end{aligned}
$$

مكن ملاحظة أن الطلاب الذين أكملوا . r دراسة من أصل Oب شخصًا. بلغت

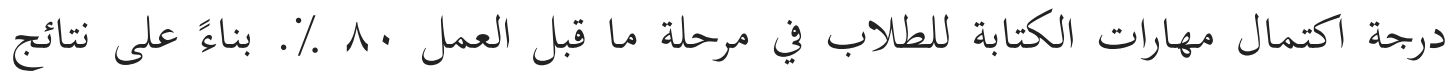
الاختبار في الدورة الثانية، سيتم إهاء هذه الدراسة لأهما وصلت إلى درجة الاكتمال المستهدفة التي تم تحديدها، وهي درجة الاستحواذ البالغة . ^ـ٪ ، على الرغم من أنه لا يزال هناك ه طلاب لم ينتهوا بعد من التعلم. 
Thariqah IImiyah; Jurnal IImu-IImu Kependidikan dan Bahasa Arab

Vol. 9. No. 2 Desember 2021

\begin{tabular}{|c|c|c|c|c|}
\hline \multirow[b]{2}{*}{ رقم } & \multirow[t]{2}{*}{ الاسم } & \multirow[b]{2}{*}{ القيمة } & \multicolumn{2}{|c|}{ كمال } \\
\hline & & & كمال & ليست كمال \\
\hline 1 & ابدل حميد & 77 & $\checkmark$ & \\
\hline 2 & احمد أريفين & 70 & $\checkmark$ & \\
\hline 3 & احمد ارياندي & 70 & $\checkmark$ & \\
\hline 4 & ايديل فهله بتوبرا & 70 & $\checkmark$ & \\
\hline 5 & الفيان سهرن & 72 & $\checkmark$ & \\
\hline 6 & دانيل سهفطرا & 73 & $\checkmark$ & \\
\hline 7 & دافيد مرتوا & 55 & & $\checkmark$ \\
\hline 8 & فهمي & 74 & $\checkmark$ & \\
\hline 9 & فريانط & 75 & $\checkmark$ & \\
\hline 10 & اكواند لوبس & 74 & $\checkmark$ & \\
\hline 11 & لحودين سمامورا & 55 & & $\checkmark$ \\
\hline 12 & محمد موليا لوبس & 70 & $\checkmark$ & \\
\hline 13 & محمد ديديت اسوال & 75 & $\checkmark$ & \\
\hline 14 & محمد سهريال & 73 & $\checkmark$ & \\
\hline
\end{tabular}


Thariqah IImiyah; Jurnal IImu-IImu Kependidikan dan Bahasa Arab

Vol. 9. No. 2 Desember 2021

\begin{tabular}{|c|c|c|c|c|}
\hline 15 & فرحان & 74 & $\checkmark$ & \\
\hline 16 & رحول انديك & 70 & $\checkmark$ & \\
\hline 17 & رزكي سهفطرا & 77 & & \\
\hline 18 & ريهان حبيبي & 25 & & $\checkmark$ \\
\hline 19 & سحيدان & 78 & $\checkmark$ & \\
\hline 20 & شولتان سيرجر & 79 & $\checkmark$ & \\
\hline 21 & سحرول رندي & 76 & $\checkmark$ & \\
\hline 22 & رحمات سليح & 70 & $\checkmark$ & \\
\hline 23 & توفق الحم & 75 & $\checkmark$ & \\
\hline 24 & وحيودي رمبي & 60 & & $\checkmark$ \\
\hline 25 & واريادي & 79 & $\sqrt{ }$ & \\
\hline \multicolumn{4}{|c|}{ عدد الدرجات التي تم الحصول عليه } & 1.746 \\
\hline \multicolumn{4}{|c|}{ القيمة المتوسطة } & 69.84 \\
\hline \multicolumn{4}{|c|}{ أقص عدد من النقط } & 79 \\
\hline \multicolumn{4}{|c|}{ Nilai < KKM } & 5 \\
\hline \multicolumn{4}{|c|}{ Nilai $>$ KKM } & 20 \\
\hline \multicolumn{4}{|l|}{ غائب } & - \\
\hline
\end{tabular}


Vol. 9. No. 2 Desember 2021

$$
\text { Presentase kekuatan : } \begin{aligned}
\mathrm{P} & =\frac{\text { Jumlah siswa yang tuntas belajar }}{\text { Jumlah siswa maksimum }} \times 100 \% \\
& =\frac{20}{25} \times 100 \% \\
& =80 \%
\end{aligned}
$$

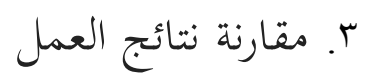

\begin{tabular}{|c|c|c|}
\hline نوع الدورة & عدد الطلاب الذين & درجة الاستحواذ \\
\hline قبل الدورة & 9 & ץ\%\% \\
\hline دورة 1 & $1 \varepsilon$ & ०.\%. \\
\hline دورة r & $r$. & $\wedge . \%$ \\
\hline
\end{tabular}

بناءً على مقارنة نتائج اختبار ما قبل الدورة ، والدورة الأولى ، والدورة الثانية

$$
\text { ، هناك زيادة كما يظهر في جدول المقارنة أدناه: }
$$

مقارنة نتائج الإجراءات السابقة للدورة، والدورة الأولى، والدورة الثانية 
Thariqah IImiyah; Jurnal IImu-IImu Kependidikan dan Bahasa Arab

Vol. 9. No. 2 Desember 2021

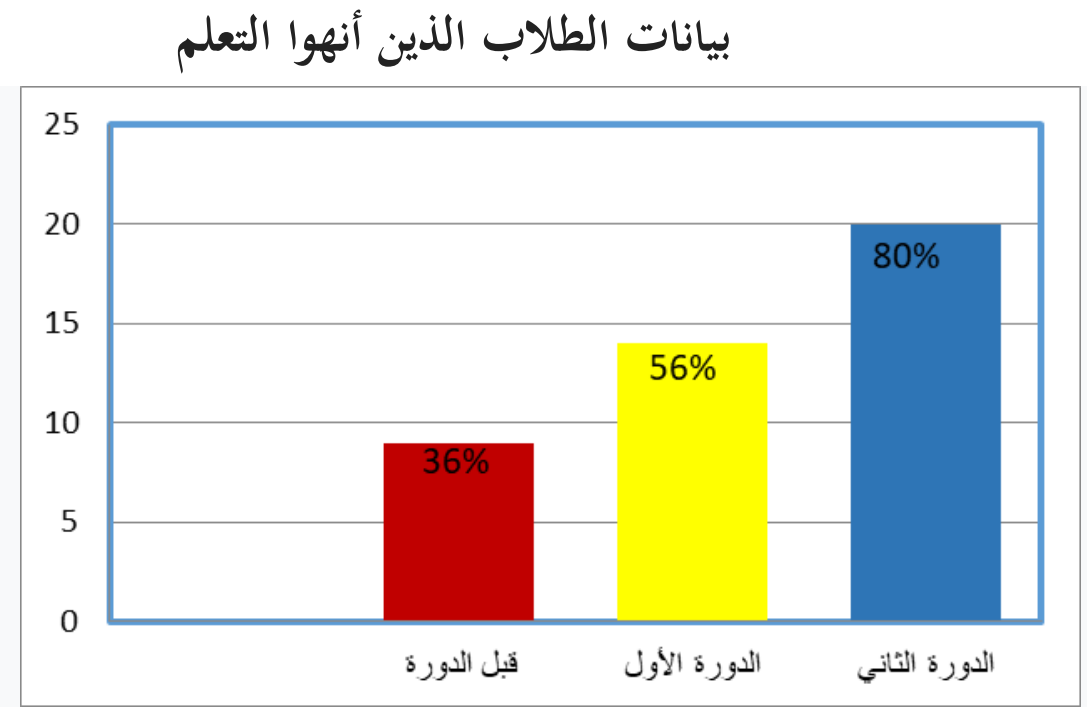

بناءً على الجدول، استمرت مهارات الكتابة في الكتابة للطلاب في الارتفاع

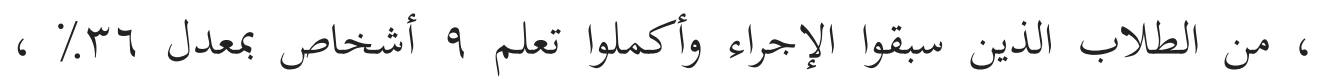
وطلاب الدورة الأولى الذين أكملوا تعلم ع ا شخصًا بنسبة جه \% ٪ ، ودورة الطلاب

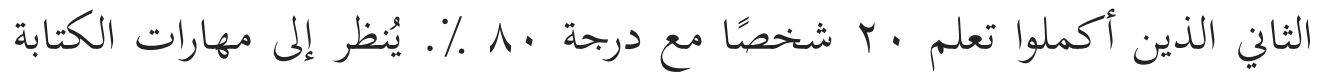
في كتابة الطلاب في ازدياد مع استخدام وسائط الصور. وسائل الصورة مناسبة للاستخدام في تعلم اللغة العربية لأفها يمكن أن تحسن من قدرات الطلاب التعليمية. من نتائج الجدول أعلاه، يمكن تقديم رسم بياني لدرجات اكتساب مهارات الكتابة للطلاب: ع ع.اختبار فرضية العمل

الفرضية في هذه الدراسة هي "استخدام وسائل الصورة يمكن أن يحسن القدرة على كتابة مقالات باللغة العربية لطلاب الصف السابع في المدرسة دارول استقامة هوتا بادانج بادابخسيديمبوان". بناءً على الأبحاث التي أجراها الباحثون، يمكن ملاحظة أن الطلاب مستمرون في الزيادة بدءًا من مرحلة ما قبل الدورة، 
والدورة الأولى، والدورة الثانية. استنادًا إلى نتائج الملاحظات التي تم إجراؤها، يمكن ملاحظة أن أنشطة الطلاب أثناء التعلم جيدة أيضًا، بدءًا من الدورة السابقة للدورة الأولى وحتى الدورة الثانية.

بناءً على نتائج الاختبار والملاحظات المذكورة أعلاه، فإن الفرضية في هذه الدراسة، وهي: استخدام وسائل الصورة يمكن أن يحسن القدرة على كتابة مقالات باللغة العربية لطلاب الصف السابع في إم تي إس دارول استقامة هوتا بادانج بادانج

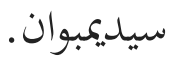

\section{الخلاصة}

استنادًا إلى نتائج البحث الذي تم إجراؤه، يمكن الاستنتاج أنه بناءً على نتائج الملاحظات والاستبيانات التي تفيد بأن الفرضية التي تنص على "استخدام وسائل الصورة في تحسين القدرة على كتابة مقالات باللغة العربية لطلاب الصف السابع من مدرسة الثنوية دار الاستيقامة هوتا بادانج بادانج سيديمبوان". الملاحظة التحسن من النتائج التي أجرى فيها البحث ملاحظات واختبارات استبيان على الطلاب الذين يكتبون المقالات العربية. ويمكن ملاحظة ذلك من نتائج الدورة السابقة ثم زيادة الدورة ا والدورة ب. لذلك فإن استخدام وسائل الصورة له تأثير كبير على نتائج تعلم الطلاب. 
Mahiyatuha wa Turuqu ، al-Maharah al-Lughawiyah، Ulyan،مد فوعد محود

$$
\text { ك) Tadrisuha }
$$

جيجيف كوستندي و بمبمنج سوتفجو، Media Pembeajaran Manual dan Digital

$$
\text { بوخور:خالييا اندنسي، (1) }
$$

احمدفرجي و ايرتا محيودين، Teknik Pembelajaran Bahasa Arab. (بندنج: فستكا

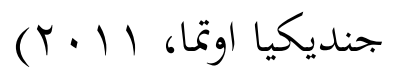

محمد ابدل حمد، Pembelajaran Bahasa Arab، (مالنج: مالنج فرس، م . . ץ)، ص.

سودروا، Beberapa Aspek Pengembangan Sumber Belajar (جاكرتا:مدياتام سرنا

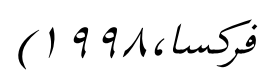

سوحرسمي اريكنط، PenelitianTindakanKelas. (جاكتا:بومي اكسرا، 0 ( • ( )

).LandasanPsikologi Proses Pendidikan نان شعودي سكمادينتا،

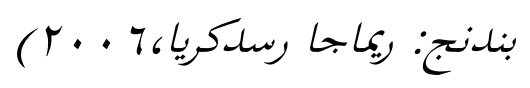

سوخيونو، Metode penelitian kuantitatif kualitatif Dan $R \& D$ (بندنج: الفبيتا، 